San Jose State University

SJSU ScholarWorks

Faculty Publications

Electrical Engineering

$1-1-2006$

\title{
A Development Framework for Hands-On Laboratory Modules in Microelectromechanical Systems (MEMS)
}

S J. Lee

San Jose State University

S Gleixner

San Jose State University

T R. Hsu

San Jose State University

David W. Parent

San Jose State University, david.parent@sjsu.edu

Follow this and additional works at: https://scholarworks.sjsu.edu/ee_pub

Part of the Electrical and Computer Engineering Commons

\section{Recommended Citation}

S J. Lee, S Gleixner, T R. Hsu, and David W. Parent. "A Development Framework for Hands-On Laboratory Modules in Microelectromechanical Systems (MEMS)" Proceedings of the ASEE Annual Meeting (2006).

This Article is brought to you for free and open access by the Electrical Engineering at SJSU ScholarWorks. It has been accepted for inclusion in Faculty Publications by an authorized administrator of SJSU ScholarWorks. For more information, please contact scholarworks@sjsu.edu. 


\section{6-2445: A DEVELOPMENT FRAMEWORK FOR HANDS-ON LABORATORY MODULES IN MICROELECTROMECHANICAL SYSTEMS (MEMS)}

\section{John Lee, San Jose State University}

JOHN LEE is an Assistant Professor in the Department of Mechanical and Aerospace

Engineering at San Jose State University. He teaches in the areas of microelectromechanical systems (MEMS), manufacturing processes, mechanical design, and dynamics. He conducts research in microfluidics and micromechanics applied to MEMS design and fabrication. Contact: sjlee@sjsu.edu.

\section{Stacy Gleixner, San Jose State University}

STACY GLEIXNER is an Assistant Professor in the Department of Chemical and Materials Engineering at San Jose State University. She teaches courses on introductory materials engineering, electronic materials, solid state kinetics and thin film deposition. Prof. Gleixner has an active research program in microelectronics and microelectromechanical systems (MEMS). Contact: gleixner@email.sjsu.edu.

\section{Tai-Ran Hsu, San Jose State University}

TAI-RAN HSU is a Professor in the Department of Mechanical and Aerospace Engineering at San Jose State University. He teaches dynamics, engineering analysis and microsystems design, manufacture and packaging. His research interest is in the electromechanical design of MEMS and reliability in assembly and packaging of microsystems. Contact: tairan@email.sjsu.edu.

\section{David Parent, San Jose State University}

DAVID PARENT is an Associate Professor in the Department of Electrical Engineering at San Jose State University. He teaches courses and conducts research in semiconductor device physics, integrated-circuit (IC) manufacturing, digital/mixed signal IC design and fabrication, and microelectromechanical systems (MEMS). Contact: dparent@email.sjsu.edu. 


\section{A Development Framework for Hands-On Laboratory Modules in Microelectromechanical Systems (MEMS)}

\section{Introduction}

Many of the most popular and advanced consumer products in recent years reveal a strong trend toward engineering more functionality in smaller dimensional scale. Examples of technology areas include wireless communication, portable audio, and digital video. Accelerometers in laptop computers, pressure sensors inside automobile tires, and micromirrors for wide-area video displays are some specific transducers that show how microelectromechanical systems (MEMS) are growing more ubiquitous in engineered systems. Other common examples include disk $\mathrm{read} /$ write heads, inkjet printing nozzles, and bio-analysis chips. ${ }^{1,2}$ Such devices add relatively little cost to engineered products, yet contribute dramatic benefits in safety, speed, reliability, and functional performance. MEMS enable new products using much less spatial volume and lower material consumption that the sensors and actuators from decades ago, and furthermore serve as an enabling bridge for the growing commitment to nanotechnology ${ }^{3}$. Multidisciplinary engineering education in MEMS is therefore essential for keeping pace with the needs and trends of modern technology.

There is a need for more enriching opportunities in MEMS education, but significant barriers and constraints limit the ways in which hands-on education is accessible to a broad learning audience. Although most engineering schools and colleges are now and may continue to be organized primarily under traditional "compartmentalized" disciplines, innovations in pedagogy and collaboration help spread MEMS and other contemporary technologies to widening audiences. However, in addition to the multidisciplinary nature of hands-on MEMS there is a very practical and fundamental problem that few universities nationwide are able to offer hands-on experience in microfabrication at the undergraduate level. So in addition to pedagogical and teamwork challenges are the often prohibitive obstacles of facilities and cost.

The most perceptible goal of the authors' present work in MEMS education is to develop an undergraduate hands-on course in MEMS, with a variety of modules to reflect a representative set of the many different applications and technologies involved. This course development project will be manifested as an interdepartmentally cross-listed course, developed in detail by the authors throughout the 2005-2006 academic year. Processing steps and some design variants will be practiced in with the help of student assistants, and the course will be offered in Fall 2006. Beyond the obvious goal of the course is a firm commitment to very active interdepartmental collaboration. In addition, we also place dedicated emphasis on empowering students with openended MEMS experiments that can be conducted even with limited resources.

This paper presents work-in-progress in terms of a framework that we have structured to support effective joint development among faculty from different engineering backgrounds, spanning mechanical engineering (ME), electrical engineering (EE), and materials engineering (MatE). The framework is organized in short instructional modules designed to span not only major 
device types and different fabrication technologies, but also different levels of resource requirements. An example of using functional prerequisites--rather than course prerequisites--is presented for one module, wherein each functional prerequisite must be satisfied by at least one member of each student team that will undertake the module. Roles of the faculty course designers are arranged to manage the complementary and essential aspects of design, fabrication, and testing. Each of these is essential to hands-on learning. As the work is still in progress, we do not present a formal set of conclusions, but do close with our observations on how these elements have served the module development process midstream.

\section{Related Work and Prior Experience}

Multidisciplinary MEMS instruction has presented a stimulating topic for engineering education in terms of specific courses ${ }^{4,5,6}$ as well as MEMS curriculum at a broader scale. ${ }^{7}$ Teaching innovations are making continual progress toward the instruction of micro-scale engineering. Recurring themes are the vital need for collaboration across multiple departments and the inherent challenge of creating an effective learning environment for students that come from different academic majors. There are many challenges and merits of multidisciplinary and interdisciplinary course development in general, and every such endeavor has many practical and organizational issues involving roles, audience, problem selection, and timing ${ }^{8}$. In addition to MEMS, other contemporary engineering topics that have drawn dedicated attention for multidisciplinary instructional development include microelectronics ${ }^{9}$ and more recently nanotechnology ${ }^{10}$.

Faculty teams at our institution (including authors of this work) have direct experience developing laboratory courses in microelectronics process engineering ${ }^{11}$ as well as in mechatronics ${ }^{12}$. These courses provide a foundation of experience in curriculum coordination and instructional module development. This experience with collaborations across materials engineering, electrical engineering, mechanical engineering, and chemical engineering highlight a history of cooperative and multidisciplinary approaches to engineering education.

This present work specifically in MEMS was preceded by a one-unit pilot course offered by one of the co-authors in Spring 2005. Scope was primarily limited to learning how relatively standard microelectronics process steps could be extended and applied to MEMS-specific structures such as silicon membrane cavities and microfluidic channels. New techniques beyond the conventional microelectronics processing taught in our other lab courses include two-sided etching, wafer bonding, ${ }^{13}$ and soft lithography. ${ }^{14}$ Although enrollment in this pilot course by coincidence had an equal balance of four mechanical engineering students and four electrical engineering students, there was no formal attention to managing student skill sets other than partnering ME students with EE students in team exercises. Limited by the one-unit time allocation, instruction focused on the fabrication processes, with little attention to design and no actual device testing. The pilot course did reveal some specific "backfill" topics because of differences in student background. This challenge of mixed backgrounds is also highlighted by other MEMS educators in related situations. ${ }^{5}$ Examples of new topics for EE students included beam theory and plate mechanics, and new ones for ME students were sheet resistance and excitation/sense principles for bridge circuits. 


\section{Challenges and Solution Strategies}

The challenges facing laboratory-based learning in MEMS are comprised of both pedagogical issues as well as practical constraints, and neither category may be underestimated. Table 1 combines some specific examples of both pedagogical and practical issues collected from related course development work as well as the authors' direct experiences. The solutions strategies that are relatively unique to the present work are highlighted by asterisk $\left(^{*}\right)$ and are discussed further below.

Table 1. Challenges for laboratory-based MEMS and proposed solution strategies.

\begin{tabular}{|l|l|}
\hline Challenge & Solution Strategy \\
\hline $\begin{array}{l}\text { Multidisciplinary content. Different methodologies, } \\
\text { terminologies, and areas of academic emphasis. }\end{array}$ & $\begin{array}{l}\text { Multidisciplinary team of course developers. All } \\
\text { project work arranged in teams that favor mixed } \\
\text { student backgrounds. }\end{array}$ \\
\hline $\begin{array}{l}\text { Varying constraints in equipment availability, } \\
\text { budget levels, and schedule. }\end{array}$ & $\begin{array}{l}\text { Flexible technical modules, selected and organized } \\
\text { based on device type as well as fabrication method. }\end{array}$ \\
\hline $\begin{array}{l}\text { Different levels of student preparation in different } \\
\text { subject areas, knowledge, and skills. }\end{array}$ & $\begin{array}{l}\text { Clearly articulated team functional prerequisites*, } \\
\text { rather than course prerequisites. }\end{array}$ \\
\hline $\begin{array}{l}\text { Lack of open-ended problem-solving opportunities, } \\
\text { limited by high demand in cost and time. }\end{array}$ & $\begin{array}{l}\text { Semi-custom design flow* and low-resolution rapid } \\
\text { prototyping*. }\end{array}$ \\
\hline Contemporary and industry relevance. & $\begin{array}{l}\text { Active engagement in applied research with } \\
\text { collaborators in industry, and case studies based on } \\
\text { current MEMS journal and conference literature. }\end{array}$ \\
\hline $\begin{array}{l}\text { Unforeseen obstacles, lack of a priori assessment } \\
\text { data on best practices. }\end{array}$ & $\begin{array}{l}\text { Formal and informal advisory relationships with } \\
\text { experienced MEMS lab developers outside our } \\
\text { local team. }\end{array}$ \\
\hline
\end{tabular}

Team Functional Prerequisites. Intentionally to reach the widest audience of students, the only mandatory course prerequisites are basic math, physics, and chemistry at the freshmen and sophomore levels. A first engineering course in materials, mechanics, or circuits is also required, but any given student is not necessarily expected to have satisfied all three of these. Instead, we have chosen to define "team functional prerequisites" (TFPs). Team functional prerequisites are an articulation of specific knowledge components that the authors have developed from our own individual disciplines (ME, EE, MatE). Through collaborative discussion, we draft, modify, and update the TFPs that are most directly relevant to MEMS.

Table 2 shows an example from part of a draft worksheet used by the authors in the process of developing a cantilever beam module that uses surface micromachining. This TFP worksheet is neither comprehensive nor complete, but reveals the emphasis on action words and designates specific assignment of a lead person or "owner" for determining what constitutes proficiency with each TFP. 
Table 2. Partial Worksheet for Team Functional Prerequisites - Cantilever Beam Module

\begin{tabular}{|l|l|l|}
\hline $\begin{array}{l}\text { Team Functional Prerequisites (TFP's) } \\
\text { To achieve significant forward progress with this module, each team must } \\
\text { have at least one member who can proficiently... }\end{array}$ & $\begin{array}{l}\text { Faculty Lead } \\
\text { (Initials) }\end{array}$ & Appears in \\
\hline $\begin{array}{l}\text { Calculate the equivalent stiffness and mechanical resonant frequency of a } \\
\text { cantilever beam }\end{array}$ & TH & ME130, E189 \\
\hline Solve a second order linear differential equation & TH & ME130, E110 \\
\hline Determine the stored energy in an RLC circuit. & DP & Phys, ME106 \\
\hline Express stored energy in complex (real \& imaginary) notation. & DP & EE98 \\
\hline Interpret the frequency plots associated with RLC filters. & DP & EE110, EE98 \\
\hline $\begin{array}{l}\text { Translate between mechanical and electrical stiffness-inertia-damping } \\
\text { modeling. }\end{array}$ & JL & $\begin{array}{l}\text { ME147, EE132, } \\
\text { ME130, ME106 }\end{array}$ \\
\hline $\begin{array}{l}\text { Calculate the electrostatic force between electrodes and relate to } \\
\text { geometric parameters. }\end{array}$ & JL & $\begin{array}{l}\text { MatE25, MatE153, } \\
\text { ME189 }\end{array}$ \\
\hline $\begin{array}{l}\text { State the characteristic dimensional scale and size limits in } \\
\text { photolithography, etching, and deposition. }\end{array}$ & $\begin{array}{l}\text { EE/MatE 129, } \\
\text { EE128, ME189 }\end{array}$ \\
\hline $\begin{array}{l}\text { Distinguish isotropic and anisotropic etching characteristics } \\
\text { EE/MatE 129, } \\
\text { ME189 }\end{array}$ \\
\hline $\begin{array}{l}\text { Calculate etch selectivity between two different materials. } \\
\text { Pattern a wafer using photolithography, including finding contrast curves. }\end{array}$ & DP & SG \\
\hline $\begin{array}{l}\text { List ways in which process variables affect the thickness and uniformity } \\
\text { oxide and metal films. }\end{array}$ & SG \\
\hline $\begin{array}{l}\text { Explain how process variables (specifically in oxidation, evaporation, and } \\
\text { annealing) affect material properties. }\end{array}$ & SG & EE/MatE 129 \\
\hline $\begin{array}{l}\text { Apply probing techniques to measure the resistance between two surface } \\
\text { contacts on a wafer }\end{array}$ & DP & EE/MatE 129 \\
\hline $\begin{array}{l}\text { Describe the environmental effects on electromechanical behavior (e.g. } \\
\text { squeeze film damping). }\end{array}$ & TH & $\begin{array}{l}\text { EE/MatE 129 } \\
\text { ME106 }\end{array}$ \\
\hline $\begin{array}{l}\text { List safety rules for working in a microelectronics fabrication laboratory. } \\
\text { ME153, }\end{array}$ & SG & ME189 \\
\hline
\end{tabular}

Also shown in the table are courses at our institution in which the prerequisites would ordinarily be met. However, it is important to emphasize that the TFPs are not course prerequisites, which experience has shown to be in conflict with promoting cross-departmental student enrollment. In many cases, individual students will lack multiple functional prerequisites for a lab module, and this is why they are expressed as team functional prerequisites. Team functional prerequisites are action-based learning objectives that are required from past experience, but not necessarily for each and every individual. An important benefit is that students are not hindered by a need to take a lengthy series of prerequisites to begin their active involvement in MEMS education. Team formation will be guided by the course instructor in a survey matching process before each module begins.

Two important features not shown in the TFP table are tracking of missing knowledge and mapping to levels of Bloom's Taxonomy. As we the course developers continue to refine the TFPs, we are not only evaluating how each module TFP maps to Bloom's levels ${ }^{15}$, but we are also uncovering specific ones that may be lacking in prior courses taken by an adequate fraction 
of prospective students. This detailed knowledge guides us in preparing short primers (tutorials), owned by the faculty lead of each TFP that requires one. Primers take various forms such as short instructor notes, independent reading assignments, or detailed equipment instructions. Primers intentionally have narrow scope according to the TFPs, such as "calculating mechanical resonant frequency of a cantilever beam" or "measuring resistance with contact probes". Aware of important observations made by others regarding overloaded course content ${ }^{5}$, we design these such that not all individuals necessarily have to be fully proficient for the team to succeed.

Semi-Custom Design Flow. The major obstacles to managing open-ended design problems ultimately come down to facilities, cost, and time. A founding goal of our project has been to enable students to synthesize new solutions in terms of design, process development, and experimental testing. Affordable prototyping becomes the pivotal factor for making open-ended problem-solving practical in terms of implementation. Students will therefore apply semi-custom design flow, a principle inherited from and practiced in integrated circuit design. ${ }^{16},{ }^{17}$ This we believe to be a creative and innovative concept that is relatively new to MEMS and especially to MEMS education. Semi-custom design involves using a partial set of common mask layouts and templates to save cost and time, while still providing opportunity for students to perform custom experiments. For example, in the cantilever beam example mentioned above, it is possible to have fixed processes for sacrificial layer deposition, (structural) metal deposition, and sacrificial etch, while opening some freedom for students to target specific design objectives (e.g. resonant frequency) by altering beam thickness and gap clearance, and even lateral dimensions using a single custom mask.

Low-Resolution Rapid Prototyping. Extensive use of lower-resolution photomasks further benefits low cost and fast turnaround time. Both of these factors have very high relative merit under the constraints of an instructional course. The cost difference is several hundreds of dollars for a traditional glass-chromium mask (that can routinely define $\sim 1$ micron features) and merely a few tens of dollars for a laser photoplotting mask (which is acceptable for $\sim 10$-micron features). ${ }^{18}$ In many cases, for instructional purposes it is not necessary to have submicron mask resolution to produce working piezoresistors, mechanical beams, or liquid microchannels, for example.

We intentionally omit reliance on external MEMS foundries to overcome wafer processing limitations. While the use of external foundry services is a very reasonable alternative, for this project we have elected to develop the fabrication sequences without required outsourcing for any of the technical modules. This challenges us to develop complete hands-on experience in $\square$ house, and also avoids reliance on funds allocated specifically for external fee-based services. We acknowledge that management of outsourcing is a valuable skill in modern industry practice, but for the current project choose to emphasize student learning by first-hand experience with hands-on processing. 


\section{Development Framework and Technical Modules}

Student Learning Objectives. In contrast to the TFPs needed for building a capable team at the onset of each MEMS module, conventional student learning objectives (SLOs) define what students should be able to do after completing a module. Table 3 shows examples of SLOs associated with the same cantilever beam module described previously.

Table 3. Student Learning Objectives - Cantilever Beam Module

Student Learning Objectives (SLO's)

Each student who fully contributes to the team and successfully completes this module will be able to...

State specific examples of practical micro sensors, actuators, or circuit components that are based on surface micromachined cantilever beams.

Select geometric parameters and material properties required to achieve a target resonant frequency for a microscale cantilever beam.

Apply oxidation, photolithography, film deposition, and etching to fabricate simple free-standing structures with air gap underneath.

Use semiconductor test instrumentation to run a frequency-swept excitation of an electrostatically actuated resonator, and determine the dominant resonant frequency.

Background Expertise. As inherent to its name, the topic of microelectromechanical systems integrates both mechanical and electrical disciplines, and these fundamentally can not be separated from materials issues. ${ }^{19}$ The makeup of our development team representing ME, EE, and MatE, covers what we see as a minimum set of combined disciplines, although we fully recognize very meaningful inputs from applied sciences and other engineering disciplines.

Functional Leadership. Aside from background discipline, we also recognize that MEMS education should concurrently address design, fabrication, and testing as three essential components. Accordingly, among ourselves we have assigned champions to each aspect. In our case we happen to have an ME investigator to lead design problem definitions, a MatE investigator to lead fabrication and process engineering, and an EE investigator to lead interfacing and testing. Other combinations are equally valid, but this scenario corresponded well with individual relative strengths. These roles establish ownership, create interdependencies, and provide checks and balances. Such organization promotes frequent dialog and puts success of the total effort in perspective across design, fabrication, and testing.

Module Organization. Rather than developing a single comprehensive exercise or term project, we have taken the strategy of using short instructional modules that allow us to articulate learning outcomes and identify levels of depth in Bloom's Taxonomy with greater specificity. ${ }^{15}$ After considering the vast variety of MEMS devices, applications, and fabrication methods, we narrowed options down to three modules for this project. Characteristics of these modules are summarized in Table 4. As is the case with integrated circuits, a rough but often correct estimate of complexity and cost is the number of masks, and these modules are arranged from most simple to most involved. 
Table 4. Characteristics of Selected MEMS Technical Modules

\begin{tabular}{|l|l|l|l|}
\hline Type of Device & Microfluidic Chip & Cantilever Beam & Silicon Membrane \\
\hline $\begin{array}{l}\text { Common MEMS } \\
\text { Applications }\end{array}$ & $\begin{array}{l}\text { Protein separation } \\
\text { Particle sorting }\end{array}$ & $\begin{array}{l}\text { RF switch } \\
\text { Resonant gate transistor }\end{array}$ & $\begin{array}{l}\text { Pressure sensor } \\
\text { Diaphragm valve }\end{array}$ \\
\hline $\begin{array}{l}\text { Examples of } \\
\text { Engineering } \\
\text { Principles }\end{array}$ & $\begin{array}{l}\text { Electrokinetic flow } \\
\text { Fluid scaling laws } \\
\text { Polymer processing }\end{array}$ & $\begin{array}{l}\text { Electrostatics } \\
\text { Resonance } \\
\text { Beam theory }\end{array}$ & $\begin{array}{l}\text { Piezoresistivity } \\
\text { Bridge networks } \\
\text { Plate deformation }\end{array}$ \\
\hline Number of Masks & 1 & 1 or 2 & 4 \\
\hline $\begin{array}{l}\text { Facilities } \\
\text { requirements }\end{array}$ & $\begin{array}{l}\text { Spin coating; UV lamp; } \\
\text { hotplate; fume hood. }\end{array}$ & $\begin{array}{l}\text { Oxidation furnace; metal } \\
\text { evaporation; } \\
\text { photolithography } \\
\text { equipment; chemical wet } \\
\text { bench. }\end{array}$ & $\begin{array}{l}\text { Oxidation/diffusion } \\
\text { furnace; metal } \\
\text { evaporation; } \\
\text { photolithography } \\
\text { equipment; chemical wet } \\
\text { bench, plasma etching, } \\
\text { wafer bonding }\end{array}$ \\
\hline
\end{tabular}

Process sequence diagrams to illustrate the two other modules (aside from the cantilever beam already discussed previously) are shown below. Figure 1 shows a microfluidic valve with a laterally-deformable membrane acting as a pinch valve, and Figure 2 shows a conventional silicon-membrane pressure sensor with piezoresistive bridge network. Aside from the functional engineering differences, what is particularly relevant for illustration in this paper is the difference in levels of complexity and corresponding resource requirements.

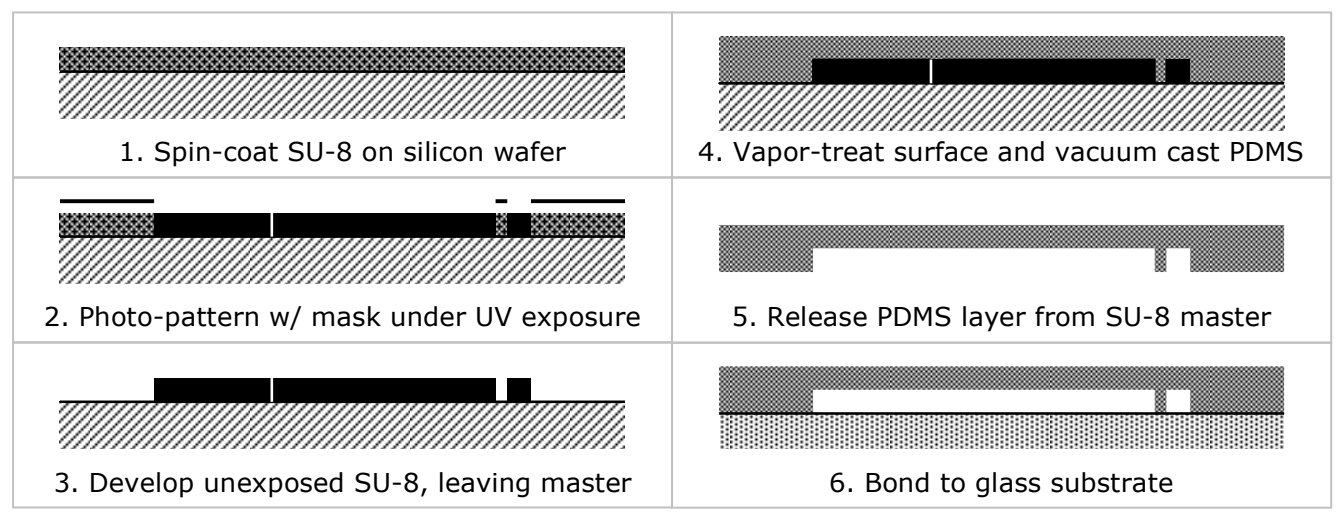

Figure 1. Process Sequence for Micro Pneumatic Valve 


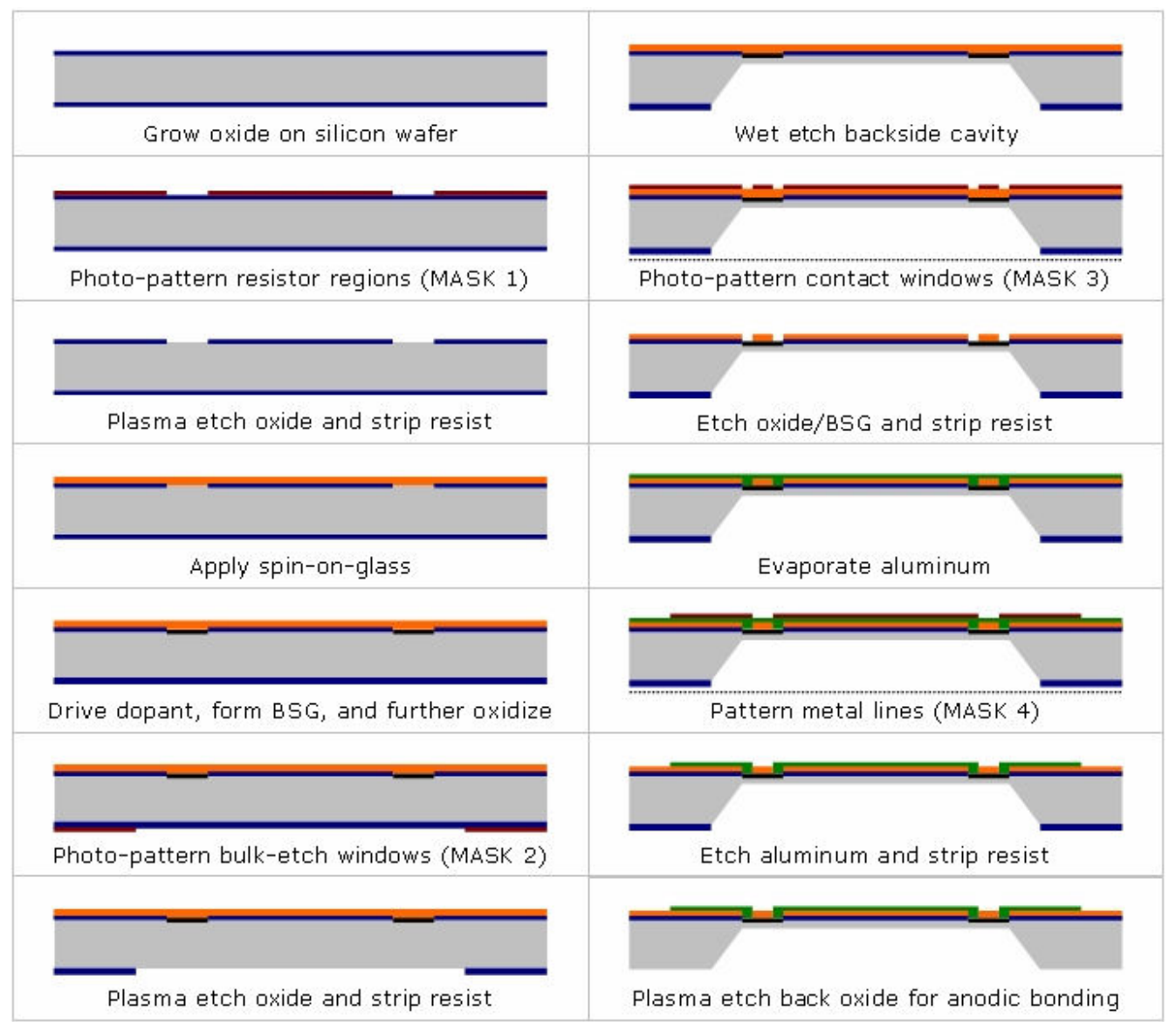

Figure 2. Process Sequence for Pressure Sensor

The microfluidic device is a relatively passive microchannel device that could be actuated in a hybrid mode with an external piezoelectric disk or electromagnetic plunger. The pressure sensor is a more complex device in which sensing elements are fully integrated within the process. However, both share the same framework of using team functional prerequisites and semicustom design flow, with assigned faculty roles to integrate design, fabrication, and testing across disciplines.

\section{Conclusions}

With the work accomplished thus far, the authors have created and continue to refine a framework and process for effective multidisciplinary collaboration in course design. From our own collective experiences and from reviewing related work, we have identified important challenges that are particularly relevant to laboratory-based MEMS education, and have proposed solution strategies. "Team functional prerequisites" and "semi-custom design flow" serve as integral parts of our approach. We have assigned cross-cutting functional leadership to cover the three aspects of design, fabrication, and testing, which are fundamental to any MEMS problem. Selection of a small set of MEMS educational modules has allowed us to capture a representative set of applications and fabrication technologies. While the modules are structured in a common framework, each has unique aspects that flexibly address scope and constraints in 
facilities, cost, and time. Summative assessment regarding the success of this effort awaits final implementation with students in Fall 2006, and presently active work includes establishing the specific assessment methods for evaluating student performance and impact.

\section{Acknowledgements}

This work is supported by a grant from the National Science Foundation (DUE Award \#0511693), and pilot work in the 2004-2005 academic year was enabled by a grant from Intel Corporation. The team is grateful for learning assessment advice from Dr. Nikos Mourtos (SJSU Professor of Aerospace Engineering), and for technical consulting from Dr. Jack Judy, based on his earlier experience with development of hands-on MEMS experiments at the University of California, Los Angeles. The authors further acknowledge the support of colleagues, staff, and student assistants of the Microelectronics Process Engineering Laboratory at San José State University.

\section{Bibliography}

1 T. R. Hsu, MEMS \& Microsystems: Design and Manufacture, Boston MA: McGraw-Hill, 2002.

2 M. Madoupi, Fundamentals of Microfabrication, Boca Raton, FL: CRC Press, 1997.

3 H. Doumanidis, "From Micro- to Nano-Manufacturing and Beyond: Making the Quantum Leap Happen", presentation document of the NSF Division of Design, Manufacture and Industrial Innovation, retrieved October 2002 from http://www.nsf.org/dmii/.

4 J. W. Judy and P. Motta, "Introduction to Micromachining and MEMS: A Lecture and Hands-On Laboratory Course for Undergraduate and Graduate Students from all Backgrounds", International Conference on Engineering Education, Manchester, England, August, 2002.

5 T. M. Adams, “An Undergraduate MEMS Course for Everyone”, Proceedings of the 2004 American Society for Engineering Education Annual Conference \&Exposition, Salt Lake City, UT, 2004, Session 3566.

6 T. R. Hsu, "Teaching ME Undergraduates in MEMS Design and Manufacture”, ASME International Mechanical Engineering Congress and Expo, November 2000, Orlando, Florida, DE-10A.

7 L. Lin, "Curriculum Development in Microelectromechanical Systems in Mechanical Engineering”, IEEE Transactions on Education, Vol. 44, No. 1, February, 2001, pp. 61-66.

8 J. R. Davis, Interdisciplinary Courses and Team Teaching: New Arrangements for Learning, Westport, CT: American Council on Education and the Oryx Press, 2002, pp. 61-64.

9 A. J. Muscat, E. L. Allen, E. D. H. Green, L. S. Vanasupa, "Interdisciplinary Teaching and Learning in a Semiconductor Processing Course", Journal of Engineering Education, October, 1998, pp. 413-421.

10 M. C. Hersam, M. Luna, G. Light, "Implementation of Interdisciplinary Group Learning and Peer Assessment in a Nanotechnology Engineering Course", Journal of Engineering Education, January 2004, pp. 49-57.

11 E. Allen, S. Gleixner, D. Parent, G. Young, Y. Dessouky and L. Vanasupa, "Microelectronics Process Engineering at San Jose State University: A Manufacturing-Oriented Interdisciplinary Degree Program," International Journal of Engineering Education, Vol. 18, No. 5, 2002. 
12 T. R. Hsu, "Development of an Undergraduate Curriculum in Mechatronics Systems Engineering", Journal of Engineering Education, April 1999, pp. 173-179.

13 Q. Y. Tong and U. Gosele, Semiconductor Wafer Bonding: Science and Technology, Hoboken, NJ: John Wiley \& Sons, Inc., 1999.

14 Y. Xia and G. M. Whitesides, "Soft Lithography”, Annual Reviews of Material Science, Vol. 28, 1998, pp. 15384.

15 R. L. Pimmel, "Student Learning of Criterion 3(a)-(k) Outcomes with Short Instructional Modules and the Relationship to Bloom's Taxonomy", Journal of Engineering Education, Oct. 2003, pp. 351-359.

16 S. M. Kang and Y. Leblebici, CMOS Digital Integrated Circuits, Boston: McGraw-Hill, 1999.

17 D. W. Parent, E. J. Basham, S. Ng, P. Weil, "An analog leaf cell for analog circuit design", Proceedings of the 2005 IEEE Int. Conf. on Microelectronic Systems Education, June 2005, pp. 11-12.

18 V. Linder, H. Wu, X. Jiang, and G. Whitesides, "Rapid Prototyping of 2D Structures with Feature Sizes Larger than $8 \mu$ m", Analytical Chemistry, Vol. 75, No. 10, 2003, pp. 2522-2527.

19 S. M. Spearing, "Materials issues in microelectromechanical systems (MEMS)", Acta Materialia, Vol. 48, No. 1, 2000, pp. 179-196. 